\title{
Structure and Mechanical Properties of Aluminum Metal Matrix Composite Produced by Hot Pressing Technique
}

\author{
M. Elmasry*, A. Elmahallawy* and M.T. Sallam*
}

\begin{abstract}
The objective of this experimental investigation is to produce a metallic matrix hybrid composite using pure aluminum as a base material reinforced with stainless steel and copper wires with different volume fraction. Hot pressing technique of laminated layers of the different constituent was used under various conditions of applied pressure, temperature, and holding time. These parameters deeply control the rate of solid state diffusion that governs the fiber / matrix interface and consequently the final mechanical properties of the obtained composites. Microstructure examination and microanalysis were carried out using scanning electron microscope equipped with energy dispersive x-ray analysis, moreover tensile mechanical properties were determined in each case. Thin continuous and uniform inetrdiffusion zone with optimum mechanical properties under a compaction pressure of 210 $\mathrm{MPa}$ at $590{ }^{\circ} \mathrm{C}$ for 120 minutes. Moreover fracture micromechanics during incremental monotonic loading proved that the outer plies are subjected to failure at the beginning of damage and then propagation through the inner plies takes place till complete failure.
\end{abstract}

Keywords: Composite, Hot pressing, Interdiffusion zone, Monotonic, Debonding, Delamination

\section{Introduction}

The demands made on materials for better overall performance are so great and diverse that no one material can satisfy them. That naturally led to a resurgence of the ancient concept of combining different materials in an integral composite material system that results in a performance unattainable by the individual constituent, and offers the great advantage of a flexible design; that is, one can, in principle, tailor-make the material as per specification of an optimum design. It implies that, if it is given the most efficient design of, an aerospace structure, an automobile, a boat, or a submarine, we can make a composite material that meets the need [1]. Metal matrix composite (MMCs) offer several advantages over other matrix composites. The principle advantage is that MMCs can be used as much higher temperature. The yield strength and modulus are higher for metals, which account for the higher transverse strength and modulus of metal matrix composites. Therefore, the metal matrix can be strengthened by various thermal and mechanical treatments [2].

Most of the commercial work on MMCs has focused on aluminum as the matrix metal because of the combination of its light weight, environmental resistance, and useful mechanical properties; that properties also make aluminum well suited for use as a matrix metal [3]. Applications of AL-MMCs include drive shafts, fan blades, and shrouds, springs, bumpers, interior panels, tires, brake shoes, clutch plates [4].Great attentions have been

\footnotetext{
* Egyptian Armed Forces.
} 
directed to the aluminum and its alloys, L.Tao and F.Delannay [5]. showed that fiber strengthening can effectively improve the creep resistance zinc-aluminum foundary alloys commonly used in the automobile industry. They showed also that the best balance of creep strength, fracture toughness, and cost was achieved when reinforcing these alloys with continuous low carbon steel fiber.D.A.Mccoyt and D.J.Lioyed [6], used an extrusion technique of a sandwich of fibers and matrix through a die at elevated temperature to fabricate a graphite fiber reinforced aluminum composite. The current work represents a new design of composite materials containing aluminum as a matrix reinforced with two different types of fibers which are stainless steel and copper fibers.

\section{Materials and Experimental Work}

In this work two main components comprises the adopted composite material, the first is the fibers which provide most of the stiffness and strength while the second component is the matrix that binds the fibers together. Pure aluminum foils with commercial quality were used as a matrix, while copper and austenitic stainless steel fibers with $250 \mu \mathrm{m}$ diameter had been implemented. The chemical compositions of the used materials are illustrated in Tables $(1,2$, 3) while their mechanical properties are given in Table (4). The structure of the produced composite consists of 5 plies of pure aluminum where the reinforcement wires were arranged between each successive plies symmetrically around the central foil so that copper wires are located in the core while the stainless steel wires are arranged near the surface as shown in Fig. (1). A standard tensile specimen according to "Standard Test Method for Tensile Properties of Fiber-Reinforced Metal Matrix Composites" [7] shown in Fig. (2) was used for the determination of tensile properties. Hot uniaxial pressing was applied using a hot press type (SANTEC) with 100 tons maximum pressure under a compaction pressure of 70, 140, $210 \mathrm{MPa}$ respectively for different temperature namely $(550,570,590){ }^{\circ} \mathrm{C}$ and various holding time in the range from 45 to 180 minutes. On the other hand reinforcement volume fraction was taken to be $\mathrm{V}_{\mathrm{f}}=5.3 \%, 7.85 \%, 10.45 \%$ and $13.08 \%$ divided equally between the two adopted types of fibers. Furthermore, to follow up the evolution of the damage criterion an incremental stepped uniaxial loading with a step fraction of the ultimate load equal 0.1 was carried. Microstructure evaluation and microanalysis were carried out by using scanning electron microscope type (SEMA 202) equipped with energy dispersive x-ray analysis. Tensile mechanical properties were determined using a universal tensile testing machine type (INSTRON 8032)

\section{Results and Discussions}

Wide range of temperature from 500 to $640^{\circ} \mathrm{C}$ was examined. However, the temperature below $550^{\circ} \mathrm{C}$ revealed a clear delamination and less filling of the interface between reinforcement wires and matrix with no clear interdiffusion zone while the temperatures over $590{ }^{\circ} \mathrm{C}$ reveal a complete diffusion and disappearance of the copper wires. Consequently, the temperature range from $550{ }^{\circ} \mathrm{C}$ to $590{ }^{\circ} \mathrm{C}$ was investigated and considered the optimum range offering regular uniform and continuous interdiffusion zone with appropriate thickness and revealed that a complete and pronounced bonding between matrix layers without delamination and voids. This indicates the occurrence of enough diffusion between these layers which transforms the matrix layers to a unit continuous material. In this temperature range, hot pressing was conducted under different holding times and pressures. Holding time was varied as follows 45, 75, 120, and 180 minutes while the initial applied hot pressing pressure at the prescribed temperatures was taken $70 \mathrm{MPa}, 140 \mathrm{MPa}$, and $210 \mathrm{MPa}$. 
An optimum parameters that reveal the adequate microstructure (thin continuous and uniform interdiffusion zone) was found as $\left(\mathrm{P}=210 \mathrm{MPa}, \mathrm{T}=590{ }^{\circ} \mathrm{C}, \mathrm{t}=120\right.$ minutes $)$ as shown in Fig. (3a). The obtained results depicted in Fig. (3) prove that the diffusion behavior is completely different between the two different types of the used reinforcements (stainless steel and copper ) where a complete diffusion of the copper wires occur in the matrix while a uniform, continuous and regular interdiffusion zone obtained in the case of stainless steel wires. The results of EDX analysis for AL-MMCs samples reinforcements with stainless steel and copper fibers prepared at $\mathrm{T}=590{ }^{\circ} \mathrm{C}, \mathrm{P}=210 \mathrm{MPa}, \mathrm{t}=120$ minutes are presented in Fig. (3b-e). Showing line distribution of the different elements through the inter phase layer.

The obtained results of the mechanical properties of the produced AL-MMCs such as tensile strength $\left(\sigma_{\mathrm{ut}}\right)$, ductility $(\delta \%)$, and toughness of the unidirectional laminate composites at constant volume fraction $\left(\mathrm{V}_{\mathrm{f}}=5.3 \%\right)$ and different hot pressing parameters are summarized in Tables $(5,6,7)$ where also the interface characteristics are demonstrated. The effects of the hot pressing holding times for different temperature on tensile strength, ductility and quasi static toughness of AL-MMCs prepared under a constant pressure of $70 \mathrm{MPa}$, are presented in Figs. $(4,5,6)$ respectively. We can note that increasing the holding time from 45 minutes to 75 minutes at a constant temperature of $590^{\circ} \mathrm{C}$ results in an increase of the ultimate strength by about $17 \%$, a decrease in ductility by about $18 \%$ and decreasing toughness by about $4 \%$. On the other hand, when the holding time is increased up to 120 minutes, the ultimate strength is increased by about $71.8 \%$, ductility is decreased by about $51.7 \%$ and toughness by about $18.3 \%$ relative to the corresponding values obtained after 45 minutes holding time. Similar behavior was recorded at $550^{\circ} \mathrm{C}$ and $570^{\circ} \mathrm{C}$ of increase of the ultimate strength and decreasing of ductility and toughness by increasing the holding time. The analysis of the effect of temperature when the holding time is kept constant showed that at a holding time of 75 minutes, the increase of the pressing temperature from $550{ }^{\circ} \mathrm{C}$ to $570{ }^{\circ} \mathrm{C}$ results in an increase in the ultimate strength by about $16 \%$ while ductility and toughness are decreased by about $20 \%$ and $5.8 \%$ respectively. On the other hand, when the temperature is raised to $590^{\circ} \mathrm{C}$, the ultimate strength is increased by about $21 \%$ while ductility and toughness are decreased by about $21.8 \%$ and $7.2 \%$ respectively. A similar behavior can be observed when the hot pressing time is prolonged up to 180 minutes. The obtained results confirm that the mechanical properties are strongly dependent on the thickness, nature, and morphology of the interdiffusion zone formed between the different fibers and the matrix. An optimum configuration of composite offering most favorable mechanical properties can be obtained after hot press of 120 minutes at $590^{\circ} \mathrm{C}$. Similar behavior was recorded at (140 and 210) $\mathrm{MPa}$ of increase of the ultimate strength and decreasing of ductility and toughness by varying the holding times and the temperatures. Figs. $(7,8,9)$ illustrate the effect of the hot pressing pressure at a constant temperature of $550^{\circ} \mathrm{C}$ and holding time of 120 minutes on the same previously mentioned properties. It can be clearly stated that the increase of pressure, in general, has a minor influence in significantly modifying the mechanical properties.

The Stress-Strain diagrams of AL-MMC samples produced under hot pressing condition of T $=590^{\circ} \mathrm{C}, \mathrm{t}=120$ minutes, and $\mathrm{P}=210 \mathrm{MPa}$ and at different fiber volume fractions are shown in Fig. (10). While their mechanical properties are presented in Table (8). The fiber volume fraction is an important parameter that can control the properties of a fiber reinforced composite material. it can be seen that by increasing the fiber volume fraction $\left(\mathrm{V}_{\mathrm{f}}\right)$ only from $5.3 \%$ to $7.85 \%$, the ultimate tensile strength (UTS) is increased by about $20 \%$ while the ductility is decreased by about $27 \%$. The corresponding increase of ultimate tensile strength when the volume fraction is increased from $5.3 \%$ to $13.08 \%$ can be reported to be in the order of 50\% which is considered a sensible high value, on the other hand there is also an important loss of the value of ductility of the same order $(50 \%)$. This implies that the proposed value of 
fiber volume fraction should be optimized to provide compromised properties of the produced composite to satisfy the destinated application.

To evaluate and study the phenomena associated with monotonic loading and to follow up the evolution of the damage criterion. Different specimens were loaded in incremental steps to various fractions of ultimate tensile strength $\left(0.1 \sigma_{\mathrm{ut}}, 0.2 \sigma_{\mathrm{ut}}, 0.3 \sigma_{\mathrm{ut}}, \ldots \ldots \sigma_{\mathrm{ut}}\right)$ after each loading step specimens were sectioned through their cross section in the middle of their gauge length and examined under Scanning Electron Microscopes, where the nature of the matrix layers deponding and fiber /matrix interaction were determined. At a loading level corresponding to $0.2 \sigma_{\mathrm{ut}}$, it was observed that a low percentage of debonding appears along the fiber/matrix interface of the outer plies, while there was no clear damage evidence in the inner plies as shown in Fig. (11). With progressive loading to a level corresponding to $0.4 \sigma_{\mathrm{u}}$, the percentage of debonding along the fiber/matrix interface was increased in the outer plies till a complete separation between the fiber and matrix was occurred. On the other hand, in the inner plies the start of debonding along the fiber/matrix interface can be observed as shown in Fig. (12). This mode of fracture is a brittle mode because it occurs mainly in the brittle intermetallic phases through the interdiffusion zone. Continued increase in uniaxial load to the level corresponding to $0.5 \sigma_{\mathrm{u}}$, a matrix crack initiation can be noticed in the outer plies. This fracture can mostly occur by a ductile mechanism because it is initiated on the fiber/matrix interface and propagated through the ductile Al-matrix. On the other hand, in the inner plies the area of debonding and the separation size between the fibers and matrix were increased as shown in Fig. (13). At a load level of $0.7 \sigma_{\mathrm{u}}$, in the outer plies, matrix cracks were emphasized and become more visible, their size was enlarged and their depth was increased while in the inner plies the progressive debonding takes place and the initiation of micro cracks can be observed as shown in Fig. (14). At a load level of $0.9 \sigma_{\mathrm{u}}$, the growth of matrix crack preceded final fracture allows an eventual coalescence of these matrix cracks in the outer plies while, in the inner plies evolution of matrix cracks becomes more visible as shown in Fig. (15). Moreover, at this high load level, another type of micro cracks appears along the boundaries of the different matrix layers together with the already observed transmatrix cracks. The evolution of these cracks will lead to delamination and separation of the matrix laminates. Immediately after, matrix failure by a ductile mode of fracture which is characterized by dimples pattern can be seen as shown in Fig. (16-a).

Finally, fiber pull-out, interface tearing and fiber fracture takes place as illustrated in Fig. (16-b). The stainless steel and copper fibers showed a cup and cone dimpled silky like fracture which can be observed in Fig. (17).

\section{Conclusions}

1-The production of Al-MMC by hot pressing technique is deeply influenced by varying the process parameters; adequate bonding between the matrix layers without delamination can not be obtained below a hot pressing temperature of $550{ }^{\circ} \mathrm{C}$.

2-The form and the rate of growth of the interphase layer (interdiffusion zone) are also strongly dependent on the hot pressing parameters T, $t$, and P. An optimum condition can be obtained in the Al-MMCs reinforced with stainless steel and copper fibers when they are prepared at $\mathrm{T}=590{ }^{\circ} \mathrm{C}, \mathrm{t}=120$ minutes, and $\mathrm{P}=210 \mathrm{MPa}$.

3-The composition of the fiber has a deep effect on the nature and morphology of the formed interface which controls the binding strength between the fibers and the matrix and consequently the total overall mechanical properties of the composite structure. Also the type, 
melting point and diffusion coefficient of alloying element of fibers are of important factors affecting the behavior of these fibers and their mutual interaction with the matrix.

4-The interdiffusion zone thickness in the range $31-48 \mu \mathrm{m}$ is considered to be optimum allowing adequate binding and in the same time secure sufficient ductility of the produced composite material.

5-Increasing fiber volume fraction results in an increase in the ultimate strength while ductility and toughness are decreased. When the volume fraction Vf is doubled an increase of ultimate tensile strength of about $50 \%$ can be achieved, while a drop of ductility of about $50 \%$ takes place which implies that the proposed value of fiber volume fraction should be optimized to provide compromised properties of the produced composite to satisfy the destinated application.

6-Failure analysis proved that damage is initiated early after loading at outer plies and propagates through inner plies until catastrophic failure occurs. The governing damage failure modes are fiber debonding, matrix cracking, delamination, and final fracture.

\section{References}

[1]. P.K. MALLICK "Composites Engineering Handbook "Marcel Dekker, Inc. 1997.

[2]. Krishan K. Chawla, "Composite Materials Science and Engineering", Springer-Verlag, 1998.

[3]. Joseph R. Davis, "Metals Handbook; Properties and Selection: Nonferrous Alloys and Special-Purpose Materials" Tenth edition vol: 2, ASM International Handbook committee, 1990.

[4]. D.Charles." Addressing the challenge of aircraft component design and manufacture from MMCs", J.Aerospace Engg., p: 1-13, 1992

[5]. L. Tao and F. Delannay "Influence of fibre interconnections on the thermomechanical behaviour of metal matrix composites consisting of a $\mathrm{Zn}-\mathrm{Al}$ alloy reinforced with steel fibres",A. Willey-Interscience Publication, 1 December 1998.

[6]. D. A. McCoy and D. J. Lloyed, "Fabrication of graphite fiber-reinforced aluminum", J. of Canadian Aeronautics and Space, vol: 33, p: 11-17, March-1987.

[7]. Manual book of ASTM Standards, "Standard Test Method for Tensile Properties of Fiber-Reinforced Metal Matrix Composites”, J.of Materials Science, vol: 1-3, July 1989.

[8]. Myer - Kutz "hand book of Materials selection", John Wiley, \& Sons Inc, 2001.

[9]. J. R. Davis, "ASM Specially Handbook: Stainless Steels," ASM International Materials Park, Ohio, 1996.

Table (1) The Chemical Composition of the Used Commercial Pure Aluminum Foils [3].

\begin{tabular}{|l||l|l|l|l|l|l|l|}
\hline Al purity & Si & Fe & Cu & V & Mn & Mg & Ti \\
\hline Min. & Max. & Max. & Max. & Max. & Max. & Max. & Max. \\
$99.5 \%$ & $0.25 \%$ & $0.4 \%$ & $0.05 \%$ & $0.05 \%$ & $0.05 \%$ & $0.05 \%$ & $0.03 \%$ \\
\hline
\end{tabular}


Table (2) The Chemical Composition of the Used Copper Fiber Type C63000 [8].

\begin{tabular}{|l||l|l|l|l|l|}
\hline AISI & $\% \mathbf{M g}$ & $\boldsymbol{\%} \mathbf{O}_{\mathbf{2}}$ & $\boldsymbol{\%} \mathbf{A l}$ & $\% \mathbf{S i}$ & $\% \mathbf{C u}$ \\
\hline & $0.21-0.24$ & $0.08-0.11$ & $0.29-0.31$ & $0.19-0.23$ & $\mathrm{R}$ \\
\hline
\end{tabular}

Table (3) Chemical Composition of the Austenitic Stainless Steel Fiber Type 304 [9].

\begin{tabular}{|l||l|l|l|l|l|l|l|l|}
\hline AISI & \% C & \% Cr & \% Ni & \% S & \% Si & \% P & \% Mn & \% Fe \\
\hline 304 & 0.08 & 20.0 & 8.0 & 0.03 & 1.0 & 0.045 & 2.0 & $\mathrm{R}$ \\
\hline
\end{tabular}

Table (4) Mechanical Properties of the Matrix [3], Copper Fiber [8] and Stainless Steel Fiber [1].

\begin{tabular}{l|ccc}
\hline \hline \multirow{2}{*}{ Properties } & \multicolumn{3}{|c}{ Metal } \\
\cline { 2 - 4 } & Aluminum matrix & Copper wire & Stainless steel wire \\
\hline \hline Elastic Modulus E $(\mathrm{GPa})$ & 70 & 121 & 198 \\
Yield Strength $\sigma_{\mathrm{y}}(\mathrm{MPa})$ & 28 & 517 & - \\
Tensile Strength $\sigma_{\mathrm{y}}(\mathrm{MPa})$ & 76 & 814 & 1400 \\
\hline \hline
\end{tabular}

Copper fibers

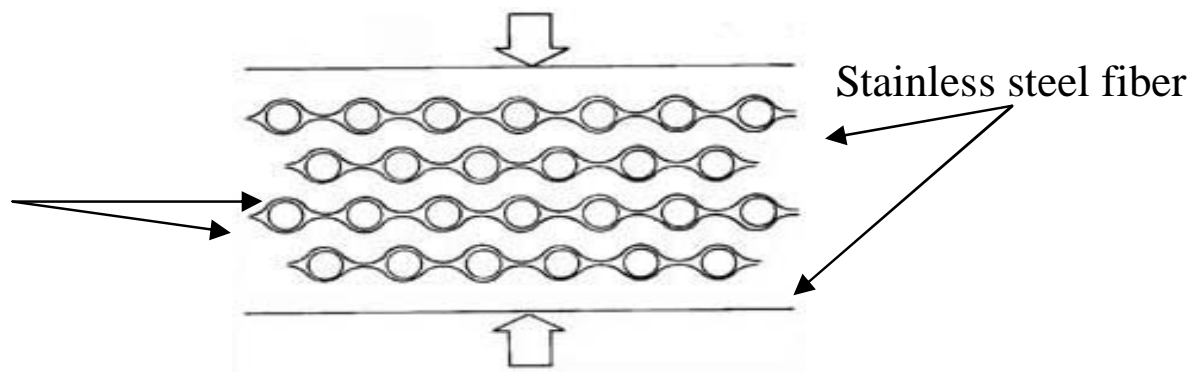

Fig. (1) Schematic Representation of the Stainless Steel, Copper Fibers/Al Foils Fabrication by Diffusion Bonding.
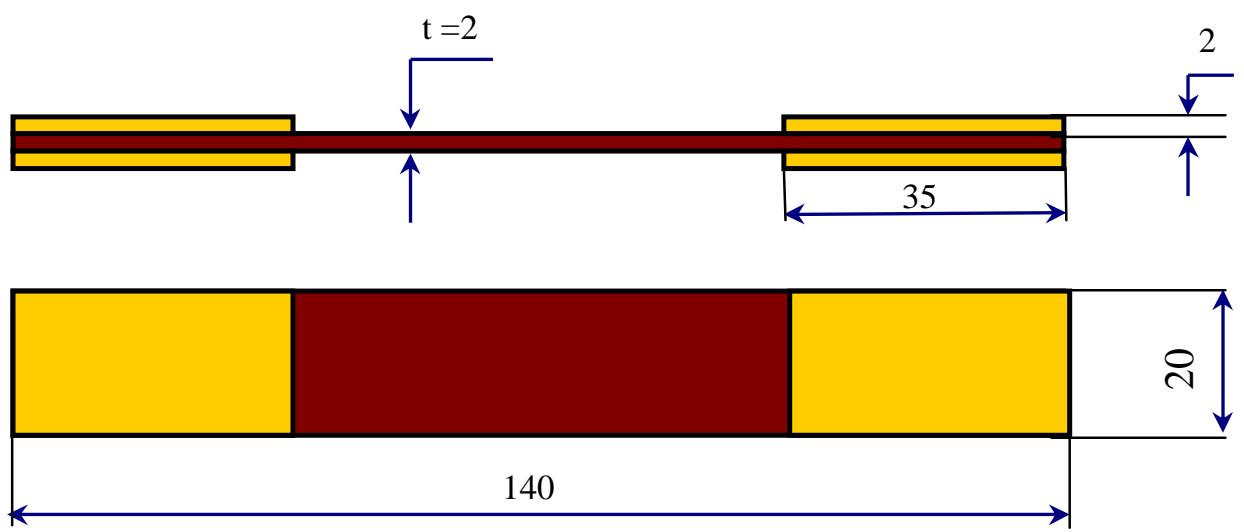

Dimensions in $\mathbf{m m}$

Fig. (2) Standard Flat Tensile Test Specimen [7]. 


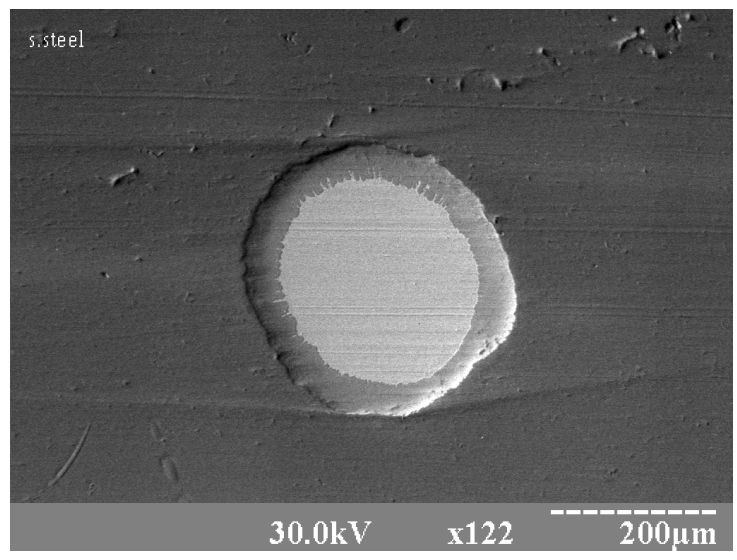

(a)

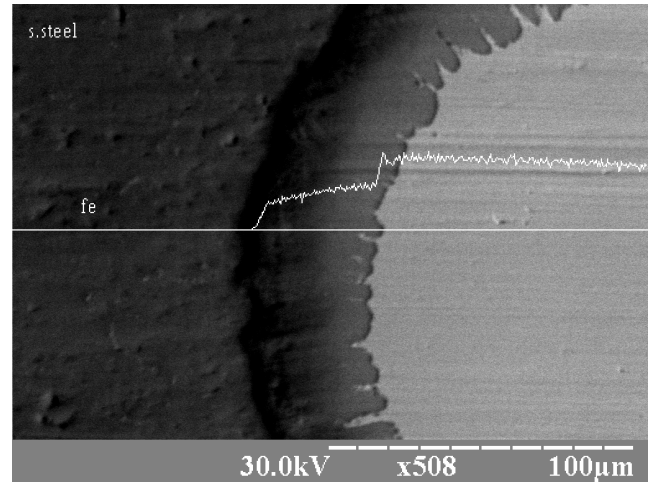

(b)

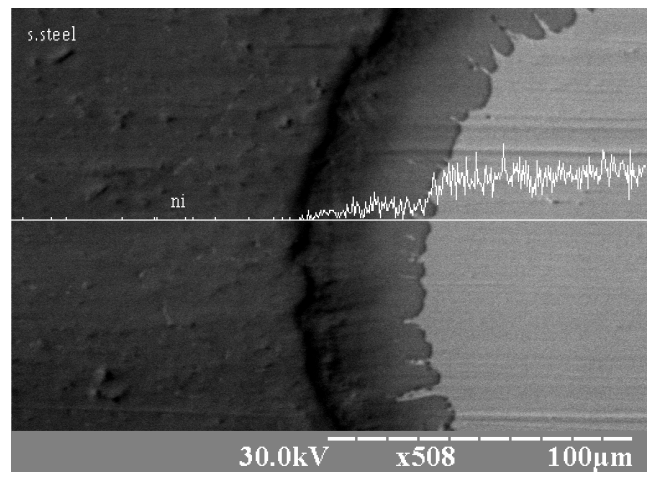

(d)

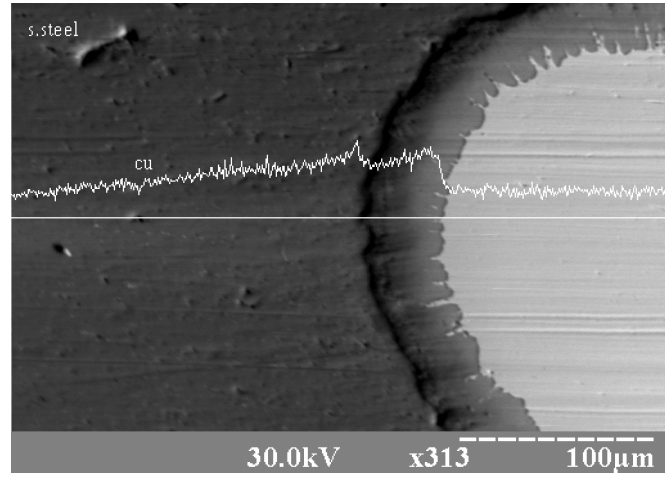

(c)

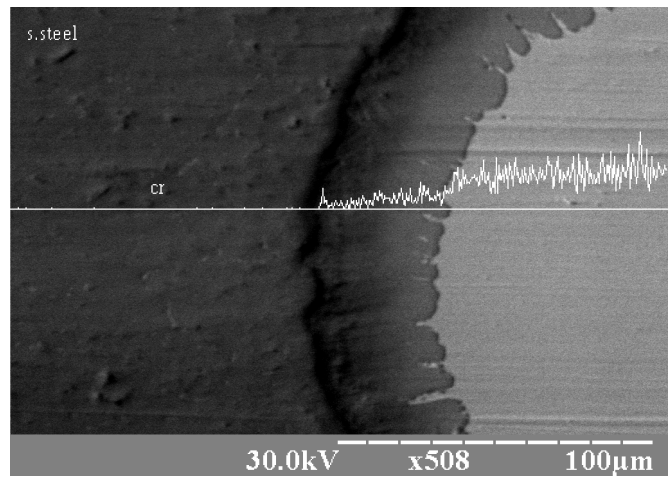

(e)

Fig. (3) Scanning Electron Micrographs of Al-Mmcs Reinforced with Stainless Steel and Copper Fibers Produced at $\mathrm{P}=210 \mathrm{MPa}, \mathrm{T}=590 \mathrm{OC}$, and Holding Times $T=(120$ Mins $)$.

(a) Interface between AL-matrix and stainless steel wires.

(b) Line microanalysis of Fe along AL-stainless steel interface.

(c) Line microanalysis of cu along AL- stainless steel interface.

(d) Line microanalysis of $\mathrm{Ni}$ along $\mathrm{AL}$-stainless steel interface.

(e) Line microanalysis of $\mathrm{Cr}$ along AL-stainless steel interface. 
Table (5) Fiber/Matrix Interface Characteristics and the Mechanical Properties at $\mathbf{P}=70 \mathrm{MPa}$.

\begin{tabular}{|c|c|c|c|c|c|c|c|c|c|}
\hline \multirow{2}{*}{\multicolumn{3}{|c|}{ Hot pressing parameters }} & \multicolumn{4}{|c|}{ Interphase characteristics } & \multicolumn{3}{|c|}{ Mechanical properties } \\
\hline & & & Copper w & & S. steel w & & & & \\
\hline \multirow[t]{5}{*}{$\begin{array}{l}\mathrm{P} \\
{[\mathrm{MPa}]}\end{array}$} & $\begin{array}{l}\mathrm{T} \\
{\left[{ }^{\circ} \mathrm{C}\right]}\end{array}$ & $\begin{array}{l}\text { H.T } \\
{[\mathrm{min}]}\end{array}$ & $\begin{array}{l}\text { Average } \\
\text { continui. } \\
(\%)\end{array}$ & $\begin{array}{l}\text { Average } \\
\text { thick- } \\
(\mu \mathrm{m})\end{array}$ & $\begin{array}{l}\text { Average } \\
\text { continui. } \\
(\%)\end{array}$ & $\begin{array}{l}\text { Average } \\
\text { thick- } \\
(\mu \mathrm{m})\end{array}$ & $\begin{array}{l}O \max \\
{[\mathrm{MPa}]}\end{array}$ & $\begin{array}{l}\delta \\
{[\%]}\end{array}$ & $\begin{array}{l}\text { toughness } \\
{[\mathrm{J}]}\end{array}$ \\
\hline & & 75 & 50 & 12.5 & - & - & 62 & 21.6 & 154.51 \\
\hline & 550 & 120 & 92 & 26 & - & - & 71 & 17.3 & 146.368 \\
\hline & & 180 & - & - & 67 & 31 & 105 & 11 & 127.31 \\
\hline & & 45 & 70 & 12 & - & - & 63 & 21.1 & 151.97 \\
\hline \multirow[t]{5}{*}{70} & 570 & 75 & 96 & 28 & - & - & 72 & 17.1 & 145.55 \\
\hline & & 120 & - & - & 70 & 33 & 107 & 10.7 & 124.436 \\
\hline & & 45 & 80 & 12.5 & - & - & 64 & 20.7 & 149.39 \\
\hline & 590 & 75 & 98 & 25 & - & - & 75 & 16.9 & 143.35 \\
\hline & & 120 & & & 70 & 48 & 110 & 10 & 122.13 \\
\hline
\end{tabular}

Table (6) Fiber/Matrix Interface Characteristics and the Mechanical Properties at P=140 MPa

Hot pressing parameters

$\begin{array}{ccc}\mathrm{P} & \mathrm{T} & \mathrm{H} . \mathrm{T} \\ {[\mathrm{MPa}]} & {\left[{ }^{\circ} \mathrm{C}\right]} & {[\mathrm{min}]}\end{array}$

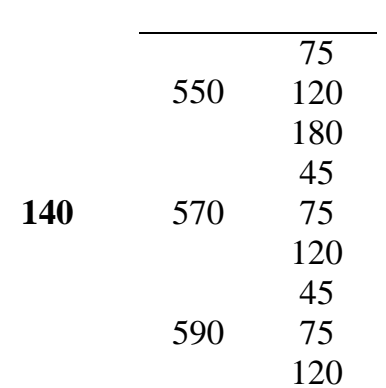

Interphase characteristics

\begin{tabular}{cccc}
\hline \multicolumn{2}{c}{ Copper wires } & \multicolumn{2}{c}{ S. steel wires } \\
\hline Average & $\begin{array}{c}\text { Average } \\
\text { thick- } \\
\text { cont. }(\%)\end{array}$ & $\begin{array}{c}\text { Average } \\
(\mu \mathrm{m})\end{array}$ & $\begin{array}{c}\text { Average } \\
\text { cont. }(\%)\end{array}$ \\
$\begin{array}{cccc}\text { thick- } \\
(\mu \mathrm{m})\end{array}$
\end{tabular}

Mechanical properties

$\begin{array}{ccc}\boldsymbol{\sigma}_{\max } & \begin{array}{c}\delta \\ {[\%]}\end{array} & \begin{array}{c}\text { toughness } \\ {[\mathrm{J}]}\end{array} \\ \begin{array}{c}\mathrm{MPa}] \\ \mathbf{6 2}\end{array} & \mathbf{2 1 . 6} & \mathbf{1 5 4 . 2 4} \\ \mathbf{7 7} & \mathbf{1 6 . 7} & \mathbf{1 4 1 . 3 4} \\ \mathbf{1 0 7} & \mathbf{1 0 . 7} & \mathbf{1 2 4 . 6 1 2} \\ \mathbf{6 3} & \mathbf{2 1 . 1} & \mathbf{1 5 1 . 5 2} \\ 79 & 16.4 & 139.14 \\ 109 & 10.1 & 122.898 \\ 65 & 20.5 & 148.79 \\ 81 & 16.1 & 134.387 \\ 116 & 9.5 & 120.685\end{array}$

Table (7) Fiber/Matrix Interface Characteristics and the Mechanical Properties at $\mathbf{P}=210 \mathrm{MPa}$

Hot pressing parameters

\begin{tabular}{|c|c|c|c|c|}
\hline \multirow{3}{*}{$\begin{array}{l}\mathrm{P} \\
{[\mathrm{MPa}]}\end{array}$} & \multirow[b]{2}{*}{$\begin{array}{l}\mathrm{T} \\
{\left[{ }^{\circ} \mathrm{C}\right]}\end{array}$} & \multicolumn{3}{|c|}{ Copper wires } \\
\hline & & $\begin{array}{l}\text { H.T } \\
{[\mathrm{min}]}\end{array}$ & $\begin{array}{l}\text { Average } \\
\text { cont. }(\%)\end{array}$ & $\begin{array}{l}\text { Averag } \\
\text { thick- } \\
\text { ( } \mu \mathrm{m})\end{array}$ \\
\hline & & 75 & 95 & 22 \\
\hline & 550 & 120 & 100 & 28 \\
\hline & & 180 & - & - \\
\hline & & 45 & 98 & 18 \\
\hline 210 & 570 & 75 & 100 & 30 \\
\hline & & 120 & - & - \\
\hline & & 45 & 100 & 20 \\
\hline & 590 & 75 & 100 & 28 \\
\hline & & 120 & - & - \\
\hline
\end{tabular}

S. steel wires

$\begin{array}{lllll}\begin{array}{l}\text { Average } \\ \text { cont. }(\%)\end{array} & \begin{array}{l}\text { Average } \\ \text { thick- } \\ (\mu \mathrm{m})\end{array} & \boldsymbol{\sigma}_{\max } & \begin{array}{l}\delta \\ {[\%]}\end{array} & \begin{array}{l}\text { toughness } \\ {[\mathrm{J}]}\end{array} \\ - & - & 64 & 20.7 & 149.38 \\ - & - & 80 & 16.3 & 137.17 \\ 85 & 100 & 114 & 9.8 & 121.685 \\ - & - & 65 & 20.5 & 148.72 \\ - & - & 81 & 16.1 & 133.21 \\ 100 & 41 & 118 & 9.4 & 117.64 \\ - & - & 67 & 20.1 & 146.21 \\ - & - & 82 & 15.9 & 132.02 \\ 100 & 48 & 121 & 9.1 & 115.35\end{array}$




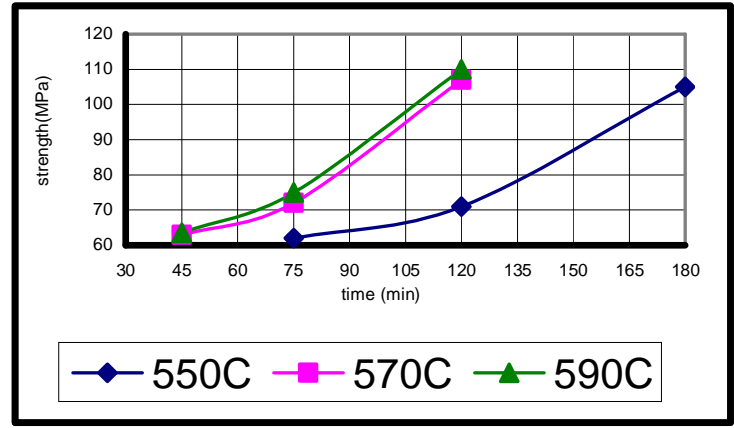

Fig (4) Strength of Al-MMC Samples Prepared by Hot Pressing at a Constant Pressure of $70 \mathrm{MPa}$ and Different Temperatures and Holding Times.

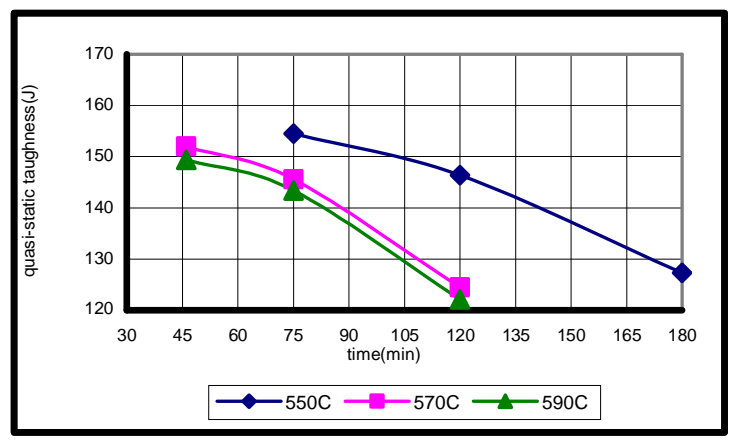

Fig (6) Quasi-Static Toughness of AlMMC Samples Prepared by Hot Pressing at a Constant Pressure of $70 \mathrm{MPa}$ and Different Temperatures and Holding Times.

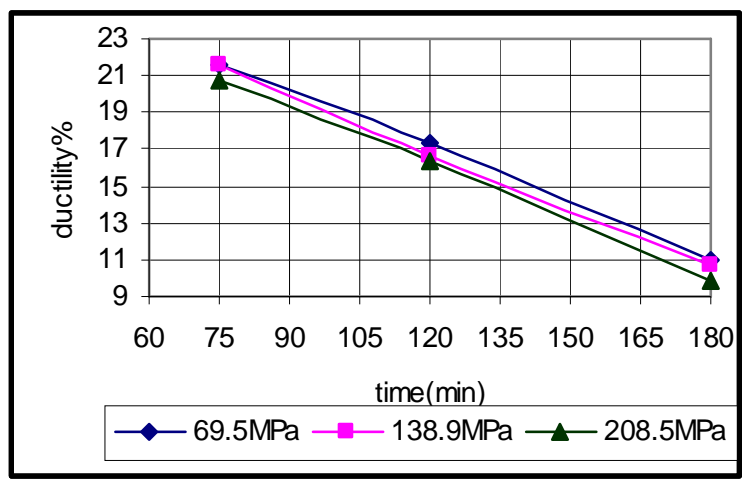

Fig (8) Strain of AL-MMCs Samples Prepared by Hot Pressing at a Constant Temperature of $550{ }^{\circ} \mathrm{C}$ and Different Pressure and Holding Times

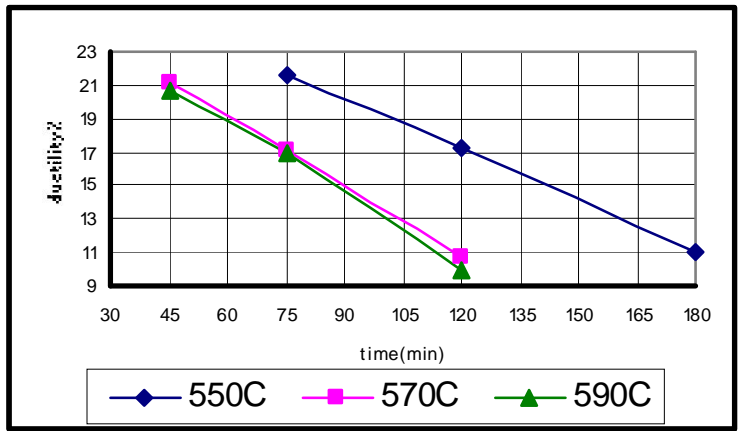

Fig (5) Ductility of Al-MMC Samples Prepared by Hot Pressing at a Constant Pressure of 70 MPa and Different Temperatures and Holding Times.

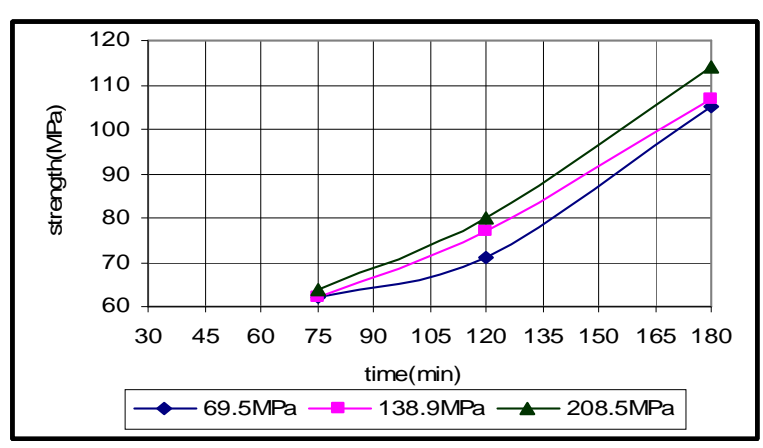

Fig (7) Strength of AL-MMCs Samples Prepared by Hot Pressing at a Constant Temperature of $550{ }^{\circ} \mathrm{C}$ and Different Pressure and Holding Times.

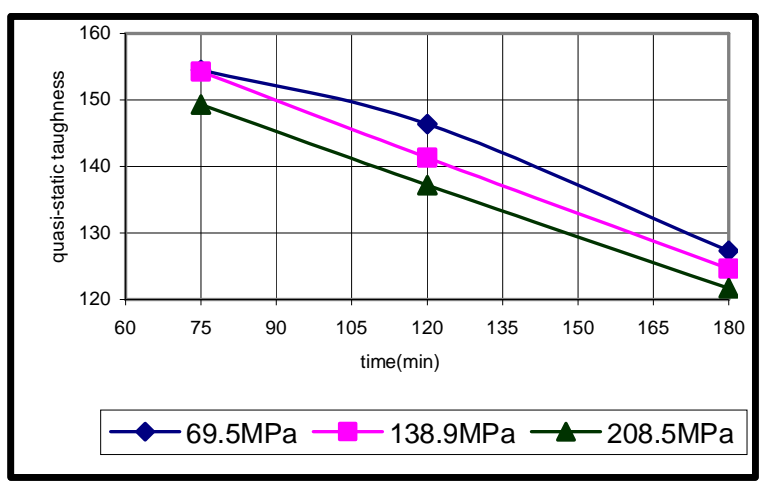

Fig (9) Quasi-Static Toughness of ALMMCs Samples Prepared by Hot Pressing at a Constant Temperature of $550{ }^{\circ} \mathrm{C}$ and Different Pressure and Holding Times 


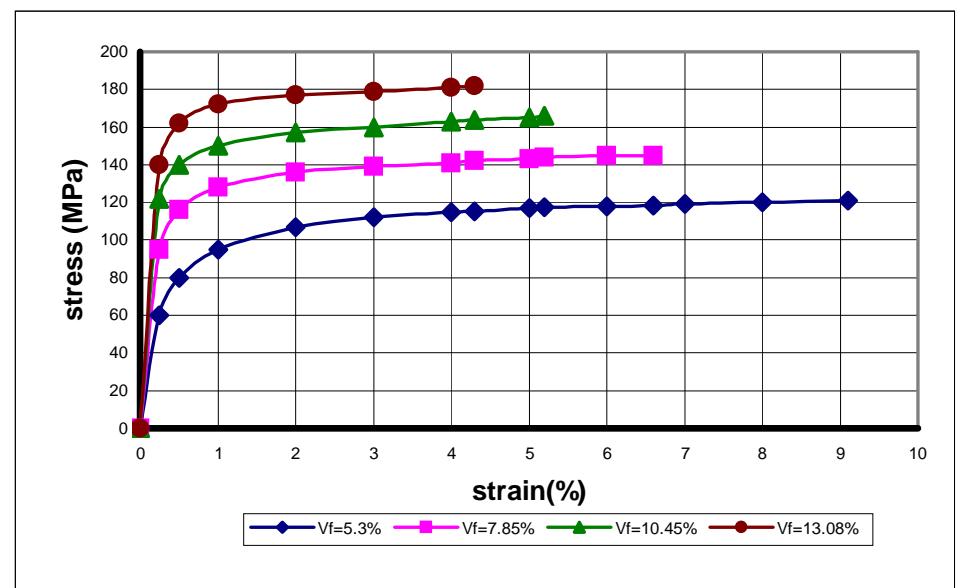

Fig (10) Stress-Strain Diagrams of Al-MMC Samples that are Prepared by Hot Pressing at $\mathrm{P}=\mathbf{2 1 0} \mathrm{MPa}, \mathrm{T}=590{ }^{\circ} \mathrm{C}$, and $\mathrm{t}=120$ Minutes and at Different Fiber Volume Fraction.

Table (8) Mechanical Properties of Test Samples Prepared at $\mathbf{T}=590^{\circ} \mathrm{C}$, $t=120$ Minutes, $P=210$ MPa, and at Different Fiber Volume Fractions.

\begin{tabular}{|l|l|l|}
\hline \multirow{2}{*}{$\begin{array}{l}\text { Test samples produced at } \\
\text { different } \mathrm{V}_{\mathrm{f}}(\boldsymbol{\%})\end{array}$} & \multicolumn{2}{|l|}{ Mechanical Properties } \\
\cline { 2 - 3 } & $\begin{array}{l}\sigma_{\max } \\
{[\mathrm{MPa}]}\end{array}$ & $\begin{array}{l}\boldsymbol{\delta} \\
{[\%]}\end{array}$ \\
\hline Monolithic Matrix $\left(\mathrm{V}_{\mathrm{f}}=0 \%\right)$ & $\mathbf{6 0}$ & $\mathbf{2 4 . 4}$ \\
\hline $\mathrm{V}_{\mathrm{f}}=5.3 \%$ & $\mathbf{1 2 1}$ & $\mathbf{9 . 1}$ \\
\hline $\mathrm{V}_{\mathrm{f}}=7.85 \%$ & $\mathbf{1 4 5}$ & $\mathbf{6 . 6}$ \\
\hline $\mathrm{V}_{\mathrm{f}}=10.45 \%$ & $\mathbf{1 6 6}$ & $\mathbf{5 . 2}$ \\
\hline $\mathrm{V}_{\mathrm{f}}=13.08 \%$ & $\mathbf{1 8 2}$ & $\mathbf{4 . 3}$ \\
\hline
\end{tabular}

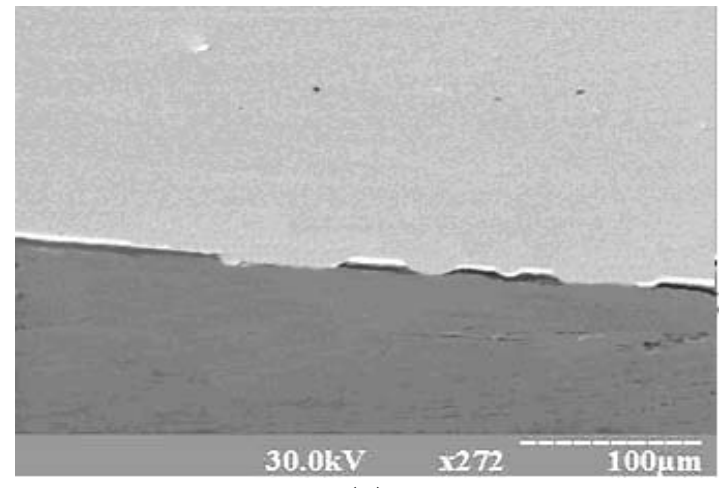

(a)

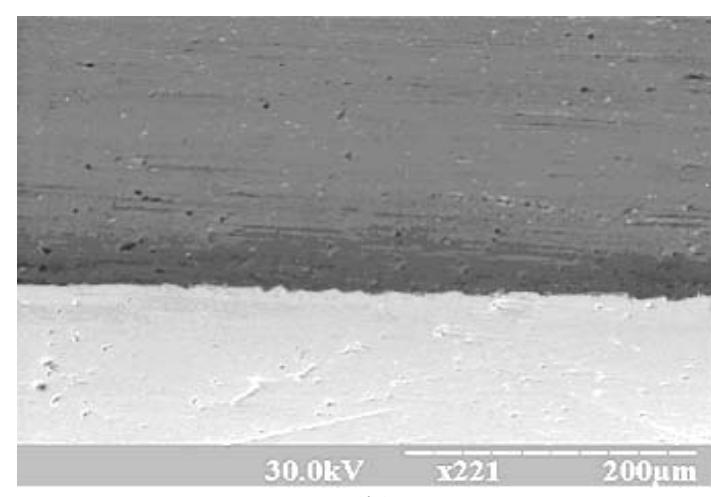

(b)

Fig. (11) Damage Mechanisms in AL-MMCs Reinforced with Stainless Steel and Copper Fibers Monotonically Loaded to $0.2 \sigma_{\mathrm{ut}}$ :

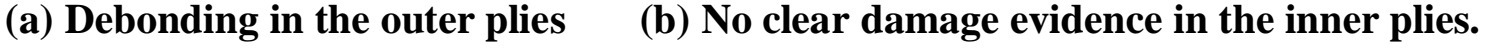




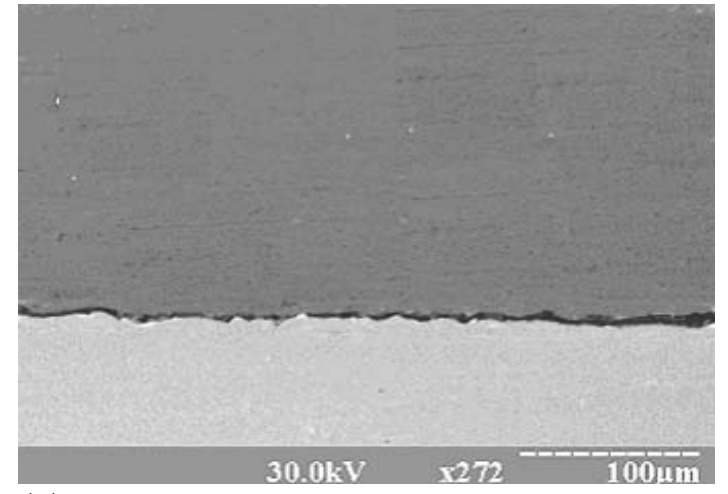

(a)

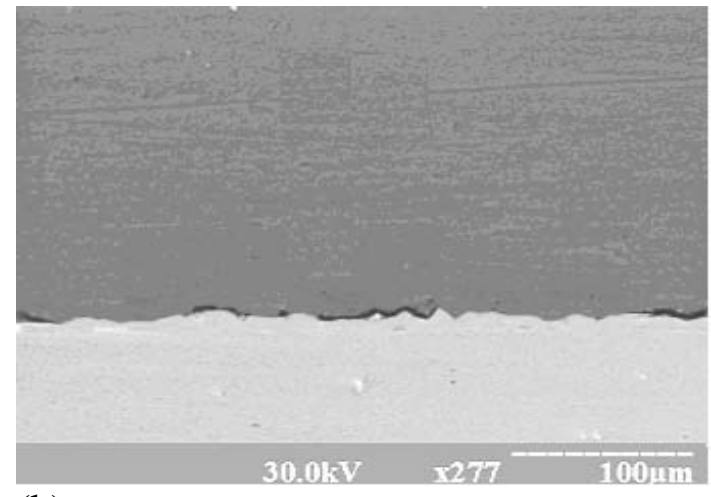

(b)

Fig. (12) Damage Mechanisms in AL-MMCs Reinforced with Stainless Steel and

Copper Fibers Monotonically Loaded to $0.4 \sigma_{\mathrm{ut}}$ :

$\begin{array}{lll}\text { (a) Further debonding in the outer ply } & \text {.(b) Low debonding in the inner ply }\end{array}$

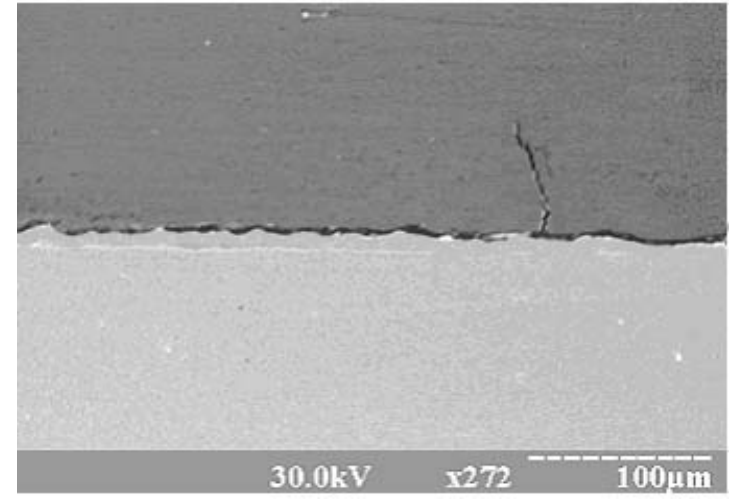

(a)

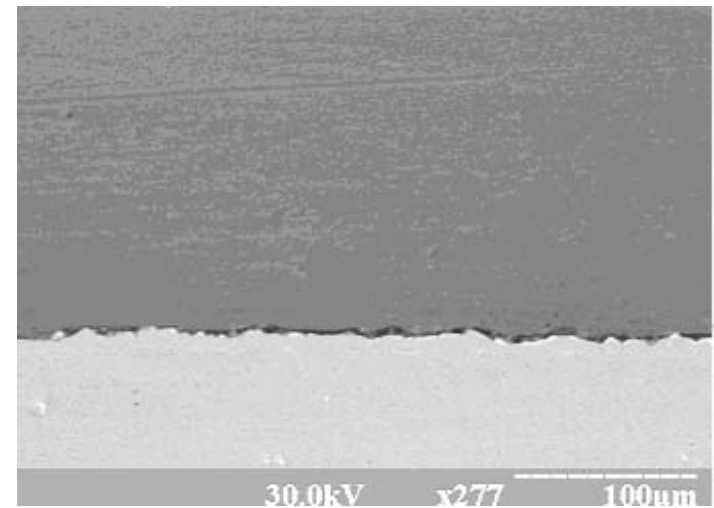

(b)

Fig. (13) Damage Mechanisms in AL-MMCs Reinforced with Stainless Steel and Copper Fibers Monotonically Loaded to 0.5бut:

(a) Further debonding and matrix crack initiation in the outer ply.

(b) Further debonding in the inner ply.

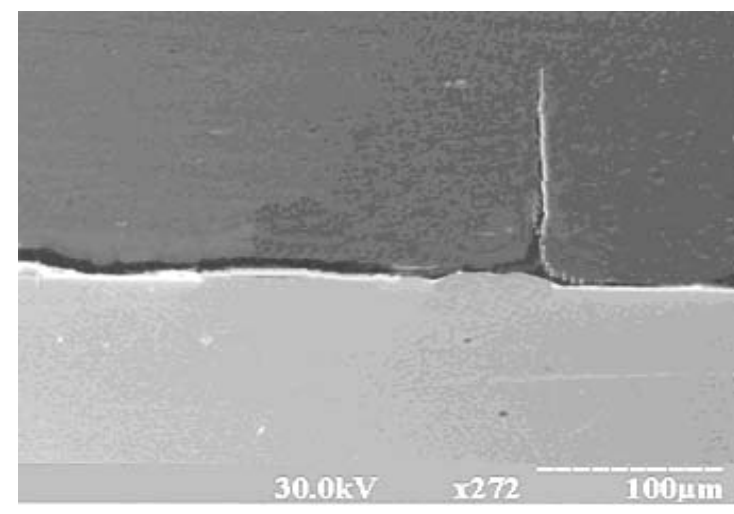

(a)

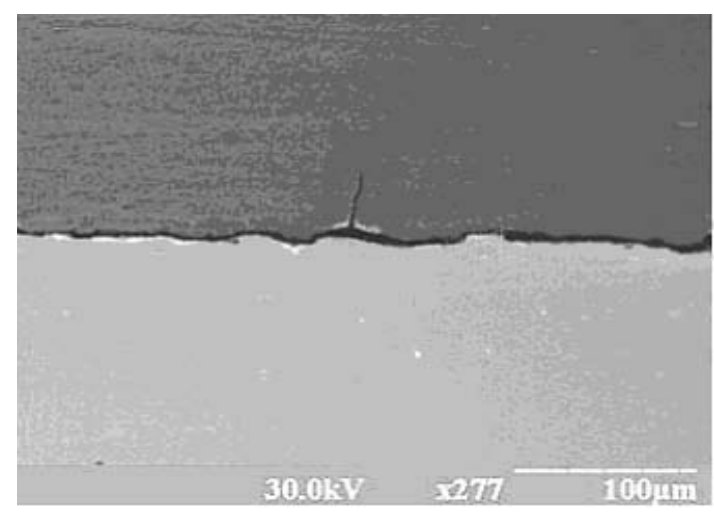

(b)

Fig. (14) Damage Mechanisms in AL-MMCs Reinforced with Stainless Steel and Copper Fibers Monotonically Loaded to 0.7 бut:

(a) Matrix crack from interfaces with debonding in the outer plies

(b) Nucleation of matrix crack from interfaces with debonding in the inner ply. 


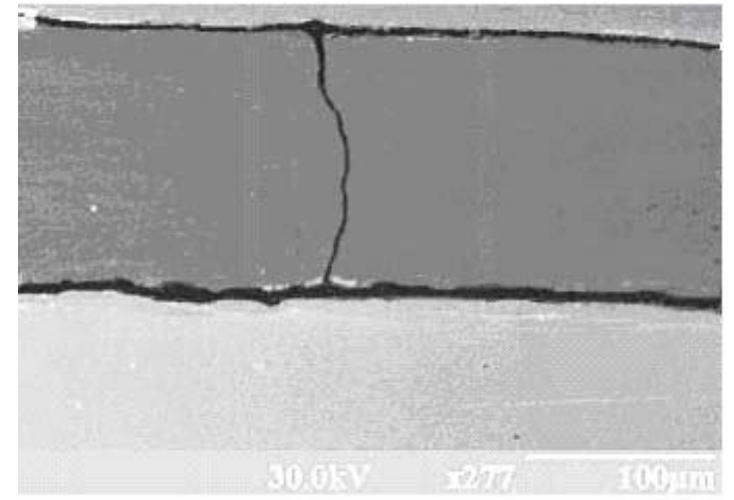

(a)

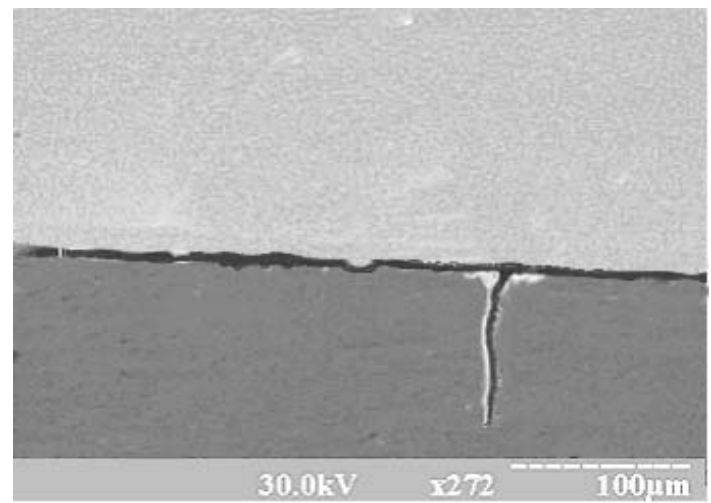

(b)

Fig. (15) Damage Mechanisms in AL-MMCs Reinforced with Stainless Steel and Copper Fibers Monotonically Loaded to 0.9бut:

(a) Matrix crack coalescence in the outer plies.

(b) Evolution of matrix cracks in the inner ply.

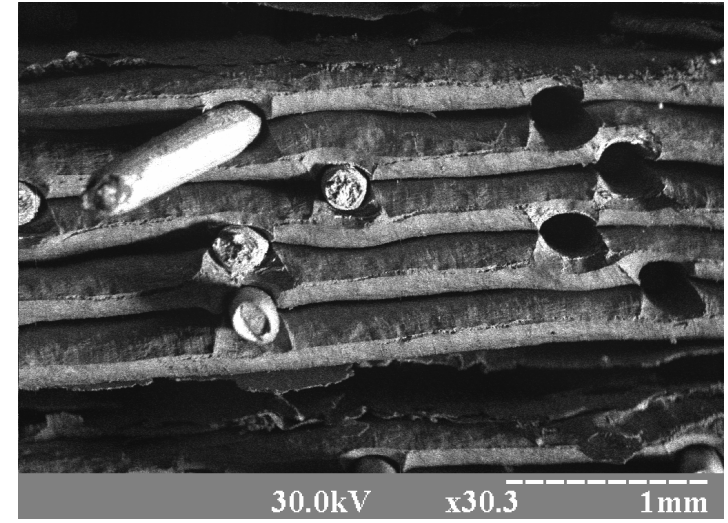

(a)

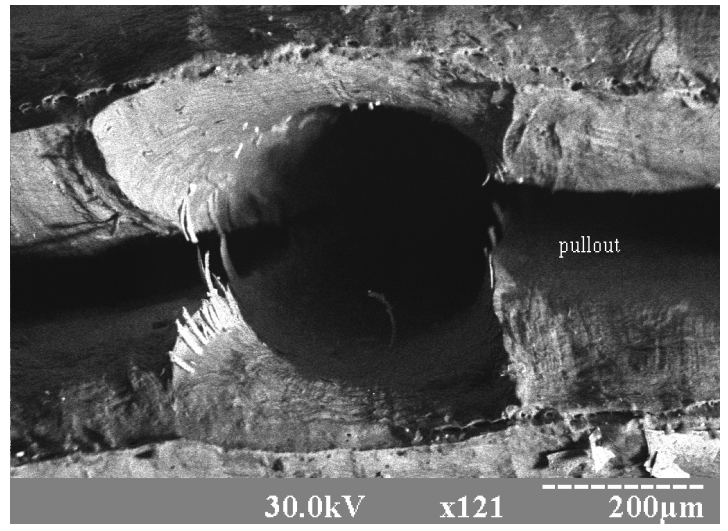

(b)

Fig. (16) Fracture Surface Morphologies of AL-MMC Sample Showing Evidence of: (a) Matrix failure by a ductile mode of fracture which is characterized by dimples pattern (delamination and separation of the matrix laminates).

(b) Fiber pull-out and interface tearing.

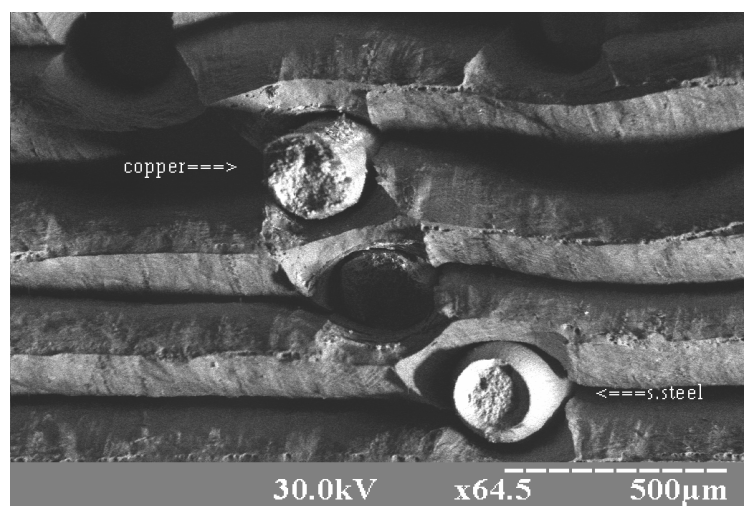

Fig. (17) Fracture Surface Morphologies of AL-MMC Sample Showing an Evidence of Cup and Cone Silky Like Fracture Modes of Fibers. 